\title{
Interferon-gamma is required for the late but not early control of Leishmania amazonensis infection in $\mathrm{C} 57 \mathrm{Bl} / 6$ mice
}

\author{
Roberta Olmo Pinheiro, Bartira Rossi-Bergmann ${ }^{+}$
}

Instituto de Biofísica Carlos Chagas Filho, Universidade Federal do Rio de Janeiro, 21949-900 Rio de Janeiro, RJ, Brasil

The critical role of interferon-gamma (IFN- $\gamma)$ in the resistance of C57Bl/6 mice to Leishmania major is widely established but its role in the relative resistance of these animals to L. amazonensis infection is still not clear. In this work we use C57Bl/6 mice congenitally deficient in the IFN- $\gamma$ gene (IFN- $\gamma \mathrm{KO}$ ) to address this issue. We found that IFN- $\gamma \mathrm{KO}$ mice were as resistant as their wild-type (WT) counterparts at least during the first two months of infection. Afterwards, whereas WT mice maintained lesion growth under control, IFN- $\gamma$ KO mice developed devastating lesions. At day 97 of infection, their lesions were 9-fold larger than WT controls, concomitant with an increased parasite burden. At this stage, lesion-draining cells from IFN- $\gamma$ KO mice had impaired capacity to produce interleukin-12 (IL-12) and tumour necrosis factor- $\alpha$ in response to parasite antigens whereas IL-4 was slightly increased in comparison to infected WT mice. Together, these results show that IFN- $\gamma$ is not critical for the initial control of L. amazonensis infection in C57Bl/6 mice, but is essencial for the developmente of a protective Th1 type immune response in the later stages.

Key words: Leishmania amazonensis - interferon-gamma - C57B1/6

Leishmaniasis is a complex of diseases caused by the obligate intracellular protozoan parasites of the genus Leishmania. The various clinical forms of human leishmaniasis have been partially reproduced in different strains of mice. For example, C57B1/6 mice infected with $L$. major develop cutaneous lesions that spontaneously heal, whereas BALB/c mice harbor non-healing cutaneous lesions. Such experimental models have earlier allowed definition of some of the immunological factors involved in resistance and susceptibility to $L$. major infection (Reiner \& Locksley 1995). During $L$. major infection of mice, a polarized differentiation of $\mathrm{Th} 1 / \mathrm{Th} 2 \mathrm{CD}^{+} \mathrm{T}$ cells occurs in resistant and susceptible mice and the Th1 cytokine interferon- $\gamma(\mathrm{IFN}-\gamma)$ plays an essential role in controlling parasite growth and disease progression (Scott 1991, Liew et al. 1997). Evidence for the critical role for IFN- $\gamma$ in the control of $L$. major infection comes from the demonstration that IFN- $\gamma$ knockout (KO) mice fail to cure infection (Wang et al. 1994).

In contrast to L. major, the immunological mechanisms determining susceptibility and resistance to $L$. amazonensis have been less studied. This is of relevance since the pathogenesis caused by L. amazonensis in humans follows a pattern different from that described for L. major and has been associated not only with localized cutaneous lesions but also with diffuse cutaneous leishmaniasis and more rarely, fatal visceral leishmaniasis (Convit et al. 1993, Almeida et al. 1996). Notably, in

Financial support: CNPq, Faperj

${ }^{+}$Corresponding author: bartira@biof.ufrj.br

Received 11 September 2006

Accepted 12 January 2007 contrast to L. major, $\mathrm{C} 57 \mathrm{Bl} / 6$ mice are susceptible to infection with $L$. amazonensis and do not heal spontaneously (Aguillar Torrentera et al. 2002a, Colmenares et al. 2003, Rosas et al. 2005).

IFN- $\gamma$ production by $\mathrm{CD} 8^{+} \mathrm{T}$ cells has been associated with immunoregulatory responses induced by leishmanial antigens that elicit significant protection against L. amazonensis (Champsi \& McMahon-Pratt 1988, Soong et al. 1997) and an overproduction of IFN- $\gamma$ seems necessary for development of a resistant phenotype (Afonso \& Scott 1993). The protective role of IFN- $\gamma$ in L. amazonensis infection is further questioned in a more recent report showing that IFN- $\gamma$ promotes the replication of $L$. amazonensis amastigotes in macrophages, as opposed to its inhibitory effect on L. major infected macrophages (Qi et al. 2004). In vivo, adoptive transfer of naïve splenocytes devoid of CD4 ${ }^{+} \mathrm{CD} 25{ }^{+}$Treg cells into RAG1-/- mice before infection markedly exacerbated disease progression, and this effect was associated with a marked production of IFN- $\gamma$ by the effector T cells (Ji et al. 2005). Since the role of IFN- $\gamma$ during $L$. amazonensis infection is not a resolved issue, in the present work we proposed to evaluate the course of $L$. amazonensis infection in IFN- $\gamma \mathrm{KO}$ mice.

\section{MATERIALS AND METHODS}

Mice - C57Bl/6-background IFN- $\gamma$ KO mice were a kind gift of Dr Leda Quércia Vieira (Gnotobiology Laboratory, Federal University of Minas Gerais, Brazil). Their cells reproducebly did not produce detectable IFN- $\gamma$ under optimal stimulatory conditions (not shown). C57Bl/ 6 wild-type mice were originally obtained from the Jackson Laboratory (Bar Harbor, Maine). All mice were used at 6-8 weeks of age.

Parasites and infection - L. amazonensis (MHOM/ $\mathrm{BR} / 75 /$ Josefa strain) promastigotes were rendered fluorescent by transfection with green fluorescent protein 
(Rossi-Bergmann et al. 1999). Parasites were periodically selected for strong fluorescence by culture in $100 \mu \mathrm{g} / \mathrm{ml}$ of geneticin. Mice were infected in the footpad with $2 \times$ $10^{6}$ stationary-growth phase promastigotes. Lesion sizes were measured with a dial caliper every 3-4 days and expressed as the difference between the thickness of infected and the contralateral non-infected footpads.

Parasite burden - The parasite loads in the infected footpads were determined by measuring the fluorescence intensity of the clarified tissue lysates (Rossi-Bergmann et al. 1999, Pinto et al. 2003). Briefly, at the end of the experiments each infected foot was skinned, individually grinded in $2 \mathrm{ml}$ of PBS and the tissue debris was removed by gravity sedimentation for $10 \mathrm{~min}$. The fluorescence intensity in twofold dilutions of the supernatants was read in triplicate in a black microtiter plate with a plate reader fluorimeter (Bio-Tek) by using excitation at $435 \mathrm{~nm}$ and emission at $538 \mathrm{~nm}$.

Cytokines - Single-cell suspensions were prepared from the popliteal lymph nodes. Cells were adjusted to $4 \times 10^{6} \%$ $\mathrm{ml}$ in Dulbecco's Minimal Essential Medium (Sigma) containing 10\% HIFCS, $20 \mathrm{mM}$ HEPES, $50 \mu \mathrm{M} 2$-mercaptoethanol, $2 \mathrm{mM}$ L-glutamine, $50 \mathrm{U} / \mathrm{ml}$ penicillin, 50 $\mu \mathrm{g} / \mathrm{ml}$ streptomycin sulfate and plated in triplicate at $0.5 \mathrm{ml}$ per well in 24-well tissue culture plates. They were then stimulated with $40 \mu \mathrm{g}$ dry weight $/ \mathrm{ml}$ of whole lysate $L$. amazonensis for $48 \mathrm{~h}$ and the levels of interleukin-4 (IL-4), IL-12, and tumour necrosis factor- $\alpha$ (TNF- $\alpha$ ) in the supernatants were measured by ELISA following the manufacturer's instructions, using recombinant cytokines as controls (R \& D Systems, Minneapolis, US).

Statistical analysis - All experiments were reproduced at least twice with very similar pattern of results, and a representative experiment is shown. The statistical differences between the groups were determined by the Student's $t$ test using the GraphPad InStat software, and were considered significant when $\mathrm{p} \leq 0.05$.

\section{RESULTS}

Role of IFN- $\gamma$ during L. amazonensis infection - The course of L. amazonensis infection was compared in WT and IFN- $\gamma$ KO mice. Fig. 1A shows that lesions in WT mice never healed during the 97-day period of infection, compatible with previous reports on the incapacity of these animals to cure L. amazonensis infection (Song et al. 1997, Aguilar Torrentera et al. 2002a, Maioli et al. 2004). IFN- $\gamma$ deficiency did not lead to more progressive disease at least during the first two months of infection, as seen by the comparable lesion sizes of IFN- $\gamma$ KO mice and WT mice. However, from day 70 of infection on, IFN- $\gamma$ KO mice developed uncontrolled growing lesions. Parasite loads were measured in the infected footpads by tissue fluorimetry on day 97 of infection. A significantly increased parasite burden was measured in the IFN- $\gamma$ KO mice (Fig. 1B), compatible with their increased lesion sizes (Fig. 1A). These findings indicate that unlike the early stages of infection when it seems unimportant, IFN- $\gamma$ is important for the control of infection in the later stages.
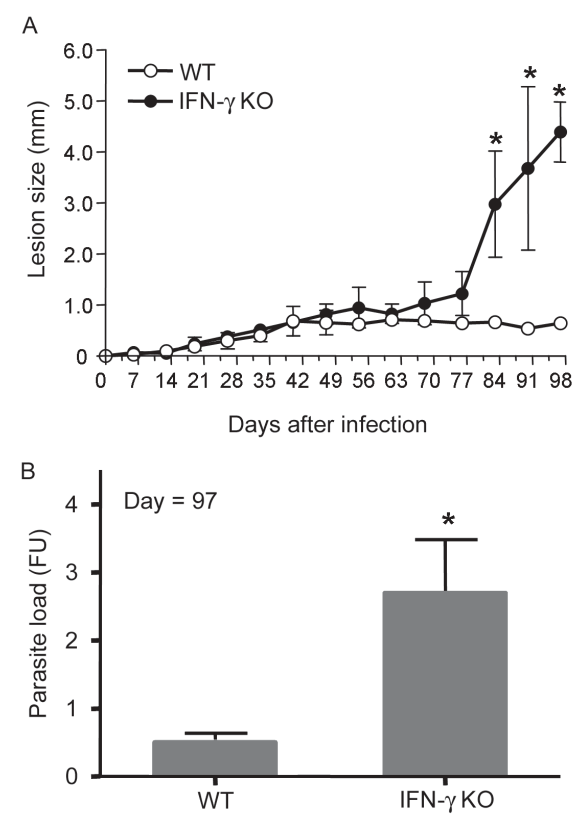

Fig. 1: Leishmania amazonensis infection in $\mathrm{C} 57 \mathrm{Bl} / 6$ and IFN- $\gamma \mathrm{KO}$ mice. C57Bl/ 6 wild-type mice (WT) and IFN- $\gamma$ knockout mice (IFN- $\gamma \mathrm{KO}$ ) were infected with $2 \times 10^{6} \mathrm{~L}$. amazonensis parasites. A: the lesion sizes were measured in the indicated days and expressed as the difference between infected and the contralateral non-infected footpad thickness; B: parasite burden was determined on day 97 of infection as described in Materials and Methods section and expressed as fluorescent units (FU). Mean $\pm \mathrm{SD}(\mathrm{n}=5) .{ }^{*} \mathrm{p} \leq 0.01$.

The cytokine production in L. amazonensis infected mice - To investigate whether IFN- $\gamma$ is important in the later stages of infection when other critical cytokines may be exhausted, the capacity of the IFN- $\gamma \mathrm{KO}$ and WT mice to respond to parasite antigens with production of interleukin IL-4, IL-12, and TNF- $\alpha$ was assessed on day 97 of infection. As expected, no IFN- $\gamma$ was detected in cell supernatants from IFN- $\gamma \mathrm{KO}$ mice, in contrast to WT mice which produced $584 \pm 43 \mathrm{pg} / \mathrm{ml}$ in response to Leishmania lysate. The results depicted in Fig. 2 shows that WT mice were much more capable to produce the Th1-type IL-12 and TNF- $\alpha$ cytokines than IFN- $\gamma$ KO mice. As to Th2 cytokines, although no differences were seen in IL-10 production (not shown), cells from IFN- $\gamma$ KO mice produced more IL-4 than cells from WT mice.

Together, those findings indicate that during later stages of L. amazonensis infection the production of IL-12 and TNF- $\alpha$ and to a lesser extent IL-4 is under the direct or indirect control of IFN- $\gamma$.

\section{DISCUSSION}

Studies of experimental Leishmania infection in mice are important to our understanding of the pathogenesis of the disease in humans. In the murine model of L. major infection, susceptibility is associated with the development of IL-4-dominated Th2 responses and resistance is associated with the development of IFN- $\gamma$ dominated Th1 responses in the infected host. The protective role of IFN- $\gamma$ on L. major infection involves microbicidal mechanisms of macrophages that effectively 

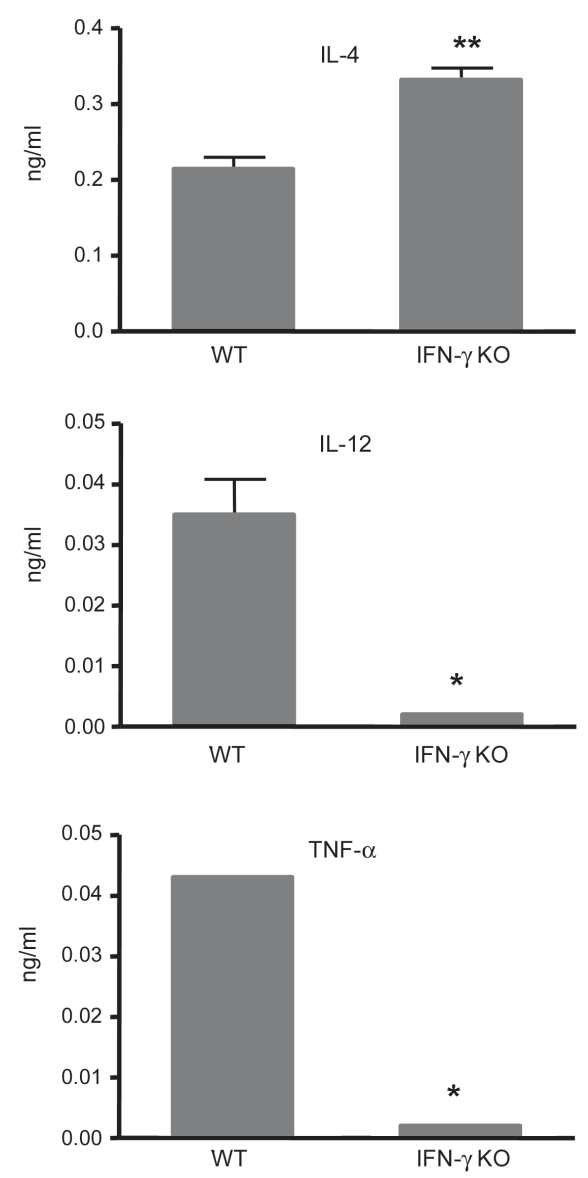

Fig. 2: cytokine pattern during uncontrolled infection in (IFN- $\gamma$ ) knockout mice. C57Bl/ 6 wild-type mice (WT) and IFN- $\gamma$ knock-out mice (IFN- $\gamma$ $\mathrm{KO})$ were infected as for Fig 1. On day 97 of infection the production of interleukin-4 (IL-4), IL-12 and tumour necrosis factor- $\alpha$ in the culture supernatants of parasite antigen- stimulated cells was measured by ELISA. Results were recorded as mean $\pm \mathrm{SD}(\mathrm{n}=3)$, and one of two independent experiments is shown. ${ }^{*} \mathrm{p} \leq 0.01, * * \mathrm{p} \leq 0.05$.

kill intracellular amastigotes (Green et al. 1990, Reiner \& Locksley 1995). The observation that MHC II (-/-), RAG2 (-/-), SCID mice (Soong et al. 1997) and CD4+depleted BALB/c mice (Silva et al. 1994) are refractory to $L$. amazonensis infection raises the possibility that $\mathrm{CD}^{+} \mathrm{T}$ cells contribute to the pathogenesis of $L$. amazonensis. This is further substantiated by a more recent finding that pathogenic $\mathrm{T}$ cells in L. amazonensis infected mice (especially $\mathrm{C} 57 \mathrm{Bl} / 6$ mice) are Th1-like cells, and elimination of functional $\mathrm{CD}^{+} \mathrm{T}$ cells prevents disease progression due to restrained cellular recruitment and local expansion of effector T cells ( $\mathrm{Ji}$ et al. 2005). These findings suggest that L. amazonensis parasites take advantage of the host IFN- $\gamma$ response for their intracellular survival. However, in other circumstances such as following protective mucosal vaccination with parasite antigens, the systemic production of IFN- $\gamma$ may be effective (Pinto et al. 2004, Pinheiro et al. 2006). Since the role of IFN- $\gamma$ during $L$. amazonensis infection is controversial, we evaluated the course of lesion growth induced by L. amazonensis in IFN- $\gamma \mathrm{KO}$ mice.
The results shown here indicating that IFN- $\gamma$ is not an important cytokine during the early period of infection are in agreement with previously reported by Colmenares et al. (2003). In that study, C57BL/6 IFN- $\gamma$ $\mathrm{KO}$ mice were also found to develop $L$. amazonensis lesions similar to WT mice during the first 10 weeks of infection. Our studies went on to show that if the course of infection is followed further, a different outcome is observed, and a protective role for IFN- $\gamma$ can be ascribed. Contrary to IFN- $\gamma$-competent WT mice, on week 14 (day 97) of infection IFN- $\gamma$ KO mice displayed overwhelming infection and poor production of TNF- $\alpha$ and IL-12 (Figs 1, 2), suggesting a protective role for those cytokines during the more chronic stage of infection. Whether or not those cytokines were also under the control of IFN- $\gamma$ during the earlier stages is not known. Apparently, the TNF- $\alpha$ induced killing of L. amazonensis by macrophages is IFN- $\gamma$-dependent (Ji et al. 2005), thus it is feasible that this cytokine was not involved in the effective control of infection seen in its earlier stages. The finding that IL-12 is important for the control of late but not early stages of $L$. mexicana infection in C57Bl/6 mice (Aguilar Torrentera 2002b) further supports the notion that mechanisms independent of IFN- $\gamma$, TNF- $\alpha$, and IL-12 are operating during the initial stages of infection of C57BL/6 mice with L. amazonensis, but further studies are needed to clarify this issue.

The pattern of cytokine production by IFN $-\gamma \mathrm{KO}$ mice also suggests that IL-4 is associated with their pronounced susceptibility. IL-4 inhibits the expression of $\beta 2$ chain of IL-12 receptor, leading to the development of a Th2 response and susceptibility (Himmelrich et al. 2000). In experiments using IL-4 KO mice, Guimarães et al. (2006) demonstrated that this cytokine is a susceptibility factor to L. amazonensis infection. Other cytokines such as IL-10 and transforming growth factor- $\beta$ (TGF- $\beta$ ) may also lead to enhanced susceptibility in BALB/c mice (Padigel et al. 2003, Pinheiro et al. 2005). In this respect, we found that IL-10 production was unaffected in IFN- $\gamma$ KO mice and that TGF- $\beta$ was not detectable in the supernatants of neither WT nor IFN- $\gamma$ KO mice (data not shown).

There are some hypotheses to explain the role of IFN- $\gamma$ during $L$. amazonensis infection. Previous work have suggested that in the absence of a secondary signal derived from other molecules like TNF- $\alpha$ or lipopolissacharide, IFN- $\gamma$ alone is inefficient to activate parasite killing mechanisms in macrophages. Insufficient levels of IFN- $\gamma$ not only fail to activate macrophages to eliminate parasite amastigotes, but rather promote parasite survival and replication within infected macrophages (Qi et al. 2004). It is possible that in the early periods of infection the secondary signal is not so strong and IFN- $\gamma$ production collaborates for lesion development. Another possibility to explain the controversial role of IFN- $\gamma$ involves the cell source of this cytokine. Since in CBA/J mice the increase in IFN- $\gamma$-producing$\mathrm{CD}^{+} \mathrm{T}$ cells is involved with protection against the disease (Rosas et al. 2005) and MHCII (-/-) mice is refractory to L. amazonensis infection (Soong et al. 1997), it 
is possible that other mechanisms may act with IFN- $\gamma$ to establish the protective role, like granule-mediated cytotoxicity or Fas-FasL pathway. Further studies will evaluate the phenotype of IFN- $\gamma$ producing cells in different stages of $L$. amazonensis infection.

In conclusion, our results show that the early control of $L$. amazonensis infection by $\mathrm{C} 57 \mathrm{Bl} / 6$ mice is independent of IFN- $\gamma$, whereas an IFN- $\gamma$-dependent Th1 response possibly involving IL- 12 and TNF- $\alpha$ may contribute to the late control of infection.

\section{ACKNOWLEDGEMENTS}

To Dr Leda Quércia Vieira (Gnotobiology Laboratory, Federal University of Minas Gerais, Brazil) for kindly providing the IFN- $\gamma \mathrm{KO}$ mice.

\section{REFERENCES}

Afonso LC, Scott P 1993. Immune responses associated with susceptibility of C57B1/10 mice to Leishmania amazonensis. Infect Immun 61: 2952-2959.

Aguilar Torrentera F, Lambot MA, Laman JD, Meurs MV, Kiss R, Noël JC, Carlier Y 2002a. Parasitic load and histopathology of cutaneous lesions, lymph node, spleen, and liver from $\mathrm{BALB} / \mathrm{c}$ and $\mathrm{C} 57 \mathrm{Bl} / 6$ mice infected with Leishmania mexicana. Am J Trop Med Hyg 66: 273-279.

Aguilar Torrentera F, Laman JD, Van Meurs M, Adorini L, Muraille E, Carlier Y 2002b. Endogenous interleukin-12 is critical for controlling the late but not the early stage of Leishmania mexicana infection in C57BL/6 mice. Infect Immun 70: 5075-5080.

Almeida RP, Barral-Netto M, de Jesus AMR, de Freitas LAR, Carvalho EM, Barral A 1996. Biological behavior of Leishmania amazonensis isolated from humans with cutaneous, mucosal, or visceral leishmaniasis in BALB/c mice. Am J Trop Med Hyg 54: 178-184.

Champsi J, McMahon-Pratt D 1988. Membrane glycoprotein M-2 protects against Leishmania amazonensis infection. Infect Immun 56: 3272-3279.

Colmenares M, Kima PE, Samoff E., Soong L, McMahon-Pratt D 2003. Perforin and gamma interferon are critical CD ${ }^{+} \mathrm{T}-$ cell-mediated responses in vaccine-induced immunity against Leishmania amazonensis infection. Infect Immun 71: 31723182.

Convit J, Ulrich M, Fernandez CT, Tapia FJ, Caceres-Dittmar G, Castes M, Rondon AJ 1993. The clinical and immunological spectrum of American cutaneous leishmaniasis. Trans $R$ Soc Trop Med Hyg 87: 444-448.

Green SJ, Meltzer MS, Hibbs JB Jr, Nacy CA 1990. Activated macrophages destroy intracellular Leishmania major amastigotes by an L- arginine-dependent killing mechanism. J Immunol 144: 278-283.

Guimarães ET, Santos LA, Ribeiro dos Santos R, Teixeira MM, dos Santos WLC, Soares MBP 2006. Role of interleukin-4 and prostaglandin $\mathrm{E}_{2}$ in Leishmania amazonensis infection of BALB/c mice. Microbes Infect 8: 1219-1226.

Himmelrich H, Launois P, Maillard I, Biedermann T, TacchiniCottier F, Locksley RM, Rocken M, Louis JA 2000. BALB/ $\mathrm{c}$ mice IL-4 production during the initial phase of infection with Leishmania major is necessary and sufficient to instruct Th2 cell development resulting in progressive disease. J Immunol 164: 4819-4825.

Ji J, Masterson J, Sun J, Soong L 2005. CD4 ${ }^{+} \mathrm{CD} 25^{+}$regulatory
$\mathrm{T}$ cells restrain pathogenic responses during Leishmania amazonensis infection. J Immunol 174: 6147-7153.

Liew FY, Wei XQ, Proudfoot L 1997. Cytokines and nitric oxide as effector molecules against parasitic infections. Philos Trans $R$ Soc Lond B Biol Sci 352: 1311-1315.

Maioli TU, Takane E, Arantes RM, Fietto JL, Afonso LC 2004. Immune response induced by New World Leishmania species in C57B1/6 mice. Parasitol Res 94: 207-212.

Padigel UM, Alexander J, Farrell JP 2003. The role of interleukin10 in susceptibility of BALB/c mice to infection with Leishmania mexicana and Leishmania amazonensis. J Immunol 171: 3705-3710.

Pinheiro RO, Fonseca EF, Lopes JRC, Guedes HLM, Fentanes RF, Rossi-Bergmann, B 2005. TGF-b-associated enhanced susceptibility to leishmaniasis following intra-muscular vaccination of mice with Leishmania amazonensis antigens. Microbes Infect 7: 1317-1323.

Pinheiro RO, Pinto EF, Guedes HLM, Filho OA, de Mattos KA, Saraiva EM, Mendonça SC, Rossi-Bergmann B 2006. Protection against cutaneous leishmaniasis by intranasal vaccination with lipophosphoglycan. Vaccine in press.

Pinto EF, de Mello Cortezia M, Rossi-Bergmann, B 2003. Interferon-gamma-inducing oral vaccination with Leishmania amazonensis antigens protects $\mathrm{BALB} / \mathrm{c}$ and $\mathrm{C} 57 \mathrm{Bl} / 6$ mice against cutaneous leishmaniasis. Vaccine 21: 3534-3541.

Pinto EF, Pinheiro RO, Rayol A, Rossi-Bergmann B 2004. Intranasal vaccination against cutaneous leishmaniasis with a particulated leishmanial antigen or DNA encoding LACK. Infect Immun 72: 4521-4527.

Qi H, Ji J, Wanasen N, Soong L 2004. Enhanced replication of Leishmania amazonensis amastigotes in gamma interferonstimulated murine macrophages: implications for the pathogenesis of cutaneous leishmaniasis. Infect Immun 72: 988-995.

Reiner SL, Locksley RM 1995. The regulation of immunity to Leishmania major. Ann Rev Immunol 13: 151-177.

Rosas LE, Keiser T, Barbi J, Satoskar AA, Septer A, Kaczmarek J, Lezama-Davila CM, Satoskar AR 2005. Genetic background influences immune responses and disease outcome of cutaneous L. mexicana infection in mice. Int Immunol 10: 1347-1357.

Rossi-Bergmann B, Lenglet A, Bezerra-Santos CR, Costa-Pinto, D, Traub-Czeko, YM 1999. Use of fluorescent Leishmania for faster quantitation of parasite growth in vitro and in vivo. Mem Inst Oswaldo Cruz 94: 74.

Scott P 1991. IFN-gamma modulates the early development of Th1 and Th2 responses in a murine model of cutaneous leishmaniasis. J Immunol 147: 3149-3155.

Silva EM, Bertho AL, Mendonca SC 1994. Effect of in vivo depletion of $\mathrm{CD}^{+} \mathrm{T}$ cells on experimental infection of susceptible BALB/c mice with Leishmania amazonensis. Acta Trop 56: $111-120$

Soong L, Chang CH, Sun J, Longley BJ, Ruddle NH, Flavell RA, McMahon-Pratt D 1997. Role of CD4+ T cells in pathogenesis associated with Leishmania amazonensis infection. J Immunol 158: 5374-5383.

Wang ZE, Reiner SL, Zheng S., Dalton DK, Locksley RM 1994. $\mathrm{CD} 4^{+}$effector cells default to the Th2 pathway in interferon- $\gamma$-deficient mice infected with Leishmania major. $J$ Exp Med 179: 1367-1371. 